Check for updates

Cite this: RSC Adv., 2017, 7, 32757

\section{Tuning the spectral, thermal and fluorescent properties of conjugated polymers via random copolymerization of hole transporting monomers $\uparrow$}

\begin{abstract}
Sapana Jadoun, Syed Marghoob Ashraf (iD $\ddagger$ and Ufana Riaz (D)*
With the aim to design conjugated copolymers of hole generating monomers, the present paper reports for the first time, ultrasonic-assisted synthesis of poly(o-phenylenediamine) and polycarbazole using different molar ratios of the two monomers. The copolymerization was established by Fourier transform infrared spectroscopy, nuclear magnetic resonance spectroscopy, ultraviolet-visible spectroscopy and differential theromogravimetric analysis while the morphology was investigated using $\mathrm{X}$-ray diffraction and transmission electron microscopy studies. The copolymer composition was confirmed by nuclear magnetic resonance spectroscopy which matched with the molar feed ratio. Reactivity ratios ( $r_{1}$ and $r_{2}$ values) confirmed random copolymerization. Infrared spectra revealed that $\int a d \bar{v}$ values increased with the
\end{abstract} increase in the poly(o-phenylenediamine) units. Cyclic voltammetry also confirmed copolymerization. Oxidation and reduction potentials corresponding to the redox peaks of o-phenylenediamine and carbazole copolymers of different composition were close to each other, but fairly different from those of the pure polymers. Redox current densities of copolymers of different compositions were found to vary with the composition. Ultraviolet-visible spectroscopy studies also revealed a progressive change in the optical properties as the copolymer composition changed from 90-10\% polycarbazole. X-ray diffraction studies showed morphology of the copolymers to be an intermediate between PCz and POPD where PCz polymer chains appeared least compact and the poly(o-phenylenediamine) chains appeared more close and compact. Fluorescence studies confirmed that as the ratio of poly(o-phenylenediamine) in the copolymer increased from 30-90\%, quantum yield increased from 0.27-0.37. Thermogravimetric analysis and differential theromogravimetric studies confirmed copolymerization of the monomers and showed two types of copolymer complexions which were consistent with the experimentally determined copolymerization ratio.
Received 25th April 2017

Accepted 21st June 2017

DOI: $10.1039 / \mathrm{c} 7 \mathrm{ra0} 4662 \mathrm{f}$

rsc.li/rsc-advances transport, via the insertion of additional charge transport layers in these polymers. ${ }^{6,7}$ Such hetero-structured devices show degraded device performance due to phase separation by recrystallization. Controlling phase separation is perhaps the most attractive approach to simultaneously facilitate charge transfer and charge transport. ${ }^{8-10}$ Chemists have found copolymerization technique to be one of the best feasible methods for the modification of various physiochemical and optoelectronic properties of homo-polymers as per end use application. ${ }^{11,12}$ Conjugated copolymer systems offer the possibility to optimize and tailor electronic and optical properties such as energy transfer and charge transfer which is not feasible in homopolymers. Improved properties can be attained which are generally intermediate between those of its pristine components. ${ }^{13,14}$ Galvin et al. ${ }^{15}$ incorporated oxadiazole units into derivatives of poly ( $p$-phenylenevinylene) (PPV), in the main chains and in the side groups which showed improved LED efficiency. Similarly, Kido et al. ${ }^{16}$ synthesized alternating copolymers of triarylamine (hole transporting) and oxadiazole (electron transporting)
Materials Research Laboratory, Department of Chemistry, Jamia Millia Islamia, New Delhi-110025, India.E-mail: ufana2002@yahoo.co.in

$\dagger$ Electronic supplementary information (ESI) available. See DOI: 10.1039/c7ra04662f

\$ Now retired. 
monomers, and demonstrated the use of this copolymer in both undoped and dye-doped LEDs.

Phenylenediamines are bifunctional monomers that can undergo branching/crosslinking when homopolymerized/ copolymerized with other monomers. ${ }^{17}$ Copolymers of $o$-phenylenediamine with aniline, ${ }^{18} 2,3$-xylidine, ${ }^{19} o$-aminophenol, ${ }^{20}$ $o$-anisidine, ${ }^{21} o$-methoxyaniline, ${ }^{22} o$-toluidine, ${ }^{23}$ and 1 -amino9,10-anthraquinone ${ }^{24}$ are well documented. Poly(carbazole) $(\mathrm{PCz})$ has been rigorously investigated for its optoelectronic properties which are applicable in hole transporting devices. ${ }^{25}$ As an organic material, PCz has many advantages because it is inexpensive and can be modulated without increasing steric hindrance near the backbone. Moreover, nitrogen atom can be easily functionalized with a large variety of substituents. ${ }^{26,27}$ This study is performed after reviewing the fact that, inspite of the remarkable performance of these two polymers; their monomers have not been copolymerized till date. To explore the hidden potential of combining hole transporting properties of individual homopolymers into one material, carbazole and $o$ phenylenediamine were chosen as key monomers for copolymerization. The effect of copolymerization on the spectral, thermal and morphological properties was investigated. The preparation of copolymers was done via ultrasonication technique. Elemental analysis, cyclic voltammetry, nuclear magnetic resonance $\left({ }^{1} \mathrm{H}-\mathrm{NMR}\right)$, Fourier transform infrared (FTIR) spectroscopy, ultraviolet-visible spectroscopy (UV-vis), fluorescence spectroscopy, thermogravimetry (TGA) and differential thermogravimetric (DTG) measurements were used to establish nature of copolymerization, optical and electronic properties. To investigate morphological features, transmission electron microscopy (TEM) and X-ray diffraction (XRD) analyses were performed.

\section{Experimental}

\section{Materials and methods}

Carbazole (Cz) (Sigma Aldrich, USA), o-phenylenediamine (Sigma Aldrich, USA), ferric chloride (Merck, India), naphthalene sulphonic acid (NSA) (Sigma Aldrich, USA), $N$-methyl-2pyrrolidone (NMP) (Merck, India), ethanol (Merck, India), tetrahydrofuran (THF) (Merck, India), hydrochloric acid (1 N $\mathrm{HCl}$ ) (Merck, India), acetonitrile (Merck, India) were used without further purification.

\section{Ultrasonic synthesis of polycarbazole (PCz) and poly $(o-$ phenylenediamine) homopolymers}

Monomer carbazole $(\mathrm{Cz})\left(1 \mathrm{~g}, 5.98 \times 10^{-3} \mathrm{~mol}\right)$ was added to $250 \mathrm{ml}$ Erlenmeyer flask containing naphthalene sulphonic acid (NSA) $\left(0.5 \mathrm{~g}, 2.4 \times 10^{-3} \mathrm{~mol}\right)$ dispersed in deionized water $(100 \mathrm{ml})$. The solution was stirred at room temperature for few minutes. Ferric chloride $\left(1.1 \mathrm{~g}, 6.17 \times 10^{-3} \mathrm{~mol}\right)$ dissolved in water $(50 \mathrm{ml})$ was added to the above reaction mixture drop by drop with the help of a burette. The flask was then ultrasonicated for $3 \mathrm{~h}$, at $25{ }^{\circ} \mathrm{C}$. Color of mixture turned green. The same was kept in deep freezer for $24 \mathrm{~h}$. The reaction mixture washed several times with distilled water to confirm the removal of excess of ferric chloride which was tested with potassium ferrocyanide. $\mathrm{PCz}$ was then dried in a vacuum oven at $70{ }^{\circ} \mathrm{C}$ for $72 \mathrm{~h}$ to ensure complete removal of impurities and water. Similar procedure was adopted for the synthesis of poly (o-phenylenediamine) (POPD) in which the color of the polymer obtained was dark brown.

\section{Ultrasonic copolymerization of carbazole and $o$ - phenylenediamine}

Synthesis of copolymers of carbazole $(\mathrm{Cz})$ and $o$-phenylenediamine (OPD) was carried out using 7 different molar ratios of $\mathrm{Cz}: \mathrm{OPD}$, that is, $90: 10,70: 30,60: 40,50: 50,40: 60,30: 70$, $10: 90$, respectively (recipe for synthesis given in ESI, Table $\mathrm{S} 1 \dagger)$. The reaction mixture was added to $250 \mathrm{ml}$ Erlenmeyer flask containing NSA $\left(0.5 \mathrm{~g}, 2.4 \times 10^{-3} \mathrm{~mol}\right)$ dispersed in deionized water $(100 \mathrm{ml})$. The solution was stirred at room temperature for $20 \mathrm{~min}$. Ferric chloride was added to reaction mixture in the ratio of monomer : oxidant $(1: 1 \mathrm{w} / \mathrm{w})$ drop by drop with the help of burette. The flask was then sonicated for $3 \mathrm{~h}$, at $25-30^{\circ} \mathrm{C}$ and was kept in deep freezer for $24 \mathrm{~h}$. After that, the reaction mixture washed several times with distilled water to confirm the removal of excess ferric chloride which was tested with potassium ferrocyanide. The copolymer obtained was then dried in a vacuum oven at $70{ }^{\circ} \mathrm{C}$ for $72 \mathrm{~h}$ to ensure complete removal of impurities and water.

\section{Characterization}

Elemental analysis (CHN) of the copolymers was done using a Perkin-Elmer Series II 2400 CHNS/O Analyzer. The viscosity of the homopolymers and copolymers was determined at room temperature using an Ubbehlode viscometer. Cyclic voltammetry was carried out under $\mathrm{N}_{2}$ atmosphere in three compartment cell on DY 2311 POTENTIOSTAT (Phadke Instruments, India) between the potential range indicated in each figure at $50 \mathrm{mV} \mathrm{s}^{-1}$ in concentrated $\mathrm{H}_{2} \mathrm{SO}_{4}$ using platinum wire as working electrode, a thin platinum loop wire as counter electrode, and $\mathrm{Ag} / \mathrm{AgCl}$ as reference electrode. Before each measurement, working electrode was washed and polished using velvet cloth with $1 \mu$ alumina powder. FT-IR spectra homopolymers and copolymers were taken in KBr pellets on FTIR spectrophotometer model Shimadzu IRA Affinity-1. The integrated absorption coefficient, $\int a d \bar{v}$, was determined using the IRA Affinity-1 software through Gaussian Lorentzian curve fittings. UV-visible spectra were taken on UV-visible spectrophotometer model Shimadzu UV-1800 using freshly dehydrated NMP and THF as solvents. The oscillator strength was calculated as per method reported in our earlier studies. ${ }^{28} \mathrm{X}$-ray diffraction patterns were recorded on Philips PW 3710 powder diffractometer (Nickel filtered copper $\mathrm{K} \alpha$ radiation). The $d$ spacing $(D)$ was determined using Braggs relation and crystallite size was calculated according to Scherrer equation..$^{\mathbf{2 1 , 2 8}}$ Transmission electron micrographs (TEM) were taken on Morgagni 268-D TEM, FEI, USA operated at an accelerated voltage of $120 \mathrm{kV}$. Fluorescence studies were performed on fluorescence spectrophotometer Fluorolog-3 (Horiba) by preparing solutions 
of the polymers and copolymers in NMP and THF. The quantum yield $\Phi$ was calculated as per method reported in our earlier studies. $^{28}$

\section{Theoretical background of decomposition kinetics study}

The solid state decomposition is kinetically described by the general equation

$$
\frac{\mathrm{d} u}{\mathrm{~d} t}=k_{\mathrm{T}}(u) \cdot f(u)
$$

where $k_{\mathrm{T}}(u)$ is the rate constant and $f(u)$ is a function of reaction model. The above rate constant can be equated with Arrhenius rate constant as

$$
k_{\mathrm{T}}(u)=A \cdot \exp ^{-\frac{E_{\mathrm{a}}}{R T}}
$$

where $A$ is the pre exponential factor and $E_{\mathrm{a}}$ is the activation energy, hence the rate equation can be rewritten as

$$
\frac{\mathrm{d} u}{\mathrm{~d} t}=A \cdot \exp ^{-\frac{E_{\mathrm{a}}}{R T}} \cdot f(u)
$$

where $t$ is the time and $T$ is the temperature, since

$$
\frac{\mathrm{d} u}{\mathrm{~d} t}=\frac{\mathrm{d} u}{\mathrm{~d} T} \cdot \frac{\mathrm{d} T}{\mathrm{~d} t}
$$

where $(\mathrm{d} T / \mathrm{d} t)$ is the change in temperature of decomposition/ minute or rate of heating, ${ }^{\circ} \mathrm{C} \min ^{-1}, \beta$. Hence rate equation in terms of change in temperature can be written as

$$
\frac{\mathrm{d} u}{\mathrm{~d} T}=\frac{A}{\beta} \exp ^{-\frac{E_{\mathrm{a}}}{R T}} \cdot f(u)
$$

The above equation can be resolved into usable form employing different mathematical approaches, subjecting to differential or integral treatment.

\section{Ozawa-Flynn-Wall approach}

Ozawa, Flynn and Wall ${ }^{29,30}$ developed analytical kinetic equations that are not based on any reaction model and hence are more reliable. They are widely used for determining activation energy at different heating rate and different degree of conversion. Ozawa-Flynn-Wall method, eqn (5), after using Doyle's approximation $^{31}$ can be written as

$$
g(u)=\frac{A}{\beta} 0.0084 \cdot \exp ^{\left(-1.052 \frac{E_{\mathrm{a}}}{R T}\right)}
$$

Taking logarithm of eqn (6), we can write:

$$
\ln \beta=\ln \left(\frac{A E_{\mathrm{a}}}{R g(u)}\right)-5.3305-1.052 \frac{E_{\mathrm{a}}}{R T}
$$

by plotting $\ln (\beta)$ against $1 / T$ at different degree of conversion regression lines can be obtained, the slope of these lines will give $E_{\text {a }}$, activation energy.

\section{Vyazokovin approach}

Using Coats-Redfern approximation for temperature integral, eqn (5), can be written as

$$
g(u)=\left(\frac{A / \beta R T^{2}}{E_{\mathrm{a}}}\right) \exp ^{\frac{-E_{\mathrm{a}}}{R T}}
$$

taking logarithm of eqn (8), and rearranging,

$$
\ln \left(\frac{\beta}{T^{2}}\right)=\ln \left[\frac{R A}{E_{\mathrm{a}} \cdot g(u)}\right]-\left[\frac{E_{\mathrm{a}}}{R T}\right]
$$

Regression lines can be drawn by plotting $\ln \left[\beta / T^{2}\right]$ against $1 /$ $T$ at different heating rates and at different extent of conversion. The slope of these lines will give activation energy of decomposition.

\section{Friedman approach}

Friedman method is a model free equation and is based on the rate of conversion per unit time or per unit temperature and hence is fairly reliable. Taking logarithm of eqn (5),

$$
\ln \left(\frac{\mathrm{d} u}{\mathrm{~d} t}\right)=\ln \left[\frac{A}{\beta}\right]-\left[\frac{E_{\mathrm{a}}}{R T}\right]+\ln f(u)
$$

or

$$
\ln \left(\frac{\mathrm{d} u}{\mathrm{~d} t}\right)=\ln \left[\frac{A \cdot f(u)}{\beta}\right]-\left[\frac{E_{\mathrm{a}}}{R T}\right]
$$

Thus by plotting $\ln [\mathrm{d} u / \mathrm{d} t]$ or $\ln [\beta \mathrm{d} u / \mathrm{d} T]$ vs. $1 / T$ straight lines will be obtained at different heating rate, the slope of these lies will give activation energy, $E_{\mathrm{a}}$.

Thermal decomposition was detected in terms of mass loss by using thermal analyzer model Diamond TG/DTA, Perkin Elmer, USA. The temperature change was controlled from room temperature $25^{\circ} \mathrm{C}$ to $600{ }^{\circ} \mathrm{C}$ at 3 different heating rates of $5{ }^{\circ} \mathrm{C}$, $10{ }^{\circ} \mathrm{C}$, and $15{ }^{\circ} \mathrm{C} \min ^{-1}$. The sampling segment was set as 0.5 seconds per point and was carried out at low moderate heating rates to keep possible heat/mass-transfer intrusions at minimum. A high purity nitrogen stream (99.5\% nitrogen, 0.5\% oxygen content) was continuously passed into the furnace at a flow rate of $60 \mathrm{~mL} \mathrm{~min}^{-1}$ at room temperature and atmospheric pressure.

\section{Results and discussion}

\section{Confirmation of copolymerization by CHNS, viscosity, cyclic voltammetry, FTIR and ${ }^{1} \mathrm{H}-\mathrm{NMR}$ analyses}

The homopolymers and copolymers were successfully synthesized via chemical polymerization. It was observed that the solubility of the copolymers depended upon the ratio of the monomers present (solubility data given in ESI, Table S2†). The copolymers containing higher number of POPD units were found to be completely soluble in water and most of the organic solvents, whereas the copolymers containing higher number of polycarbazole units showed poor solubility in common organic solvents but fairly good solubility in THF and NMP. Hence, the confirmation of the nature of copolymerization was carried out by $\mathrm{CHN}$ and spectral analyses as discussed in the proceeding section. 


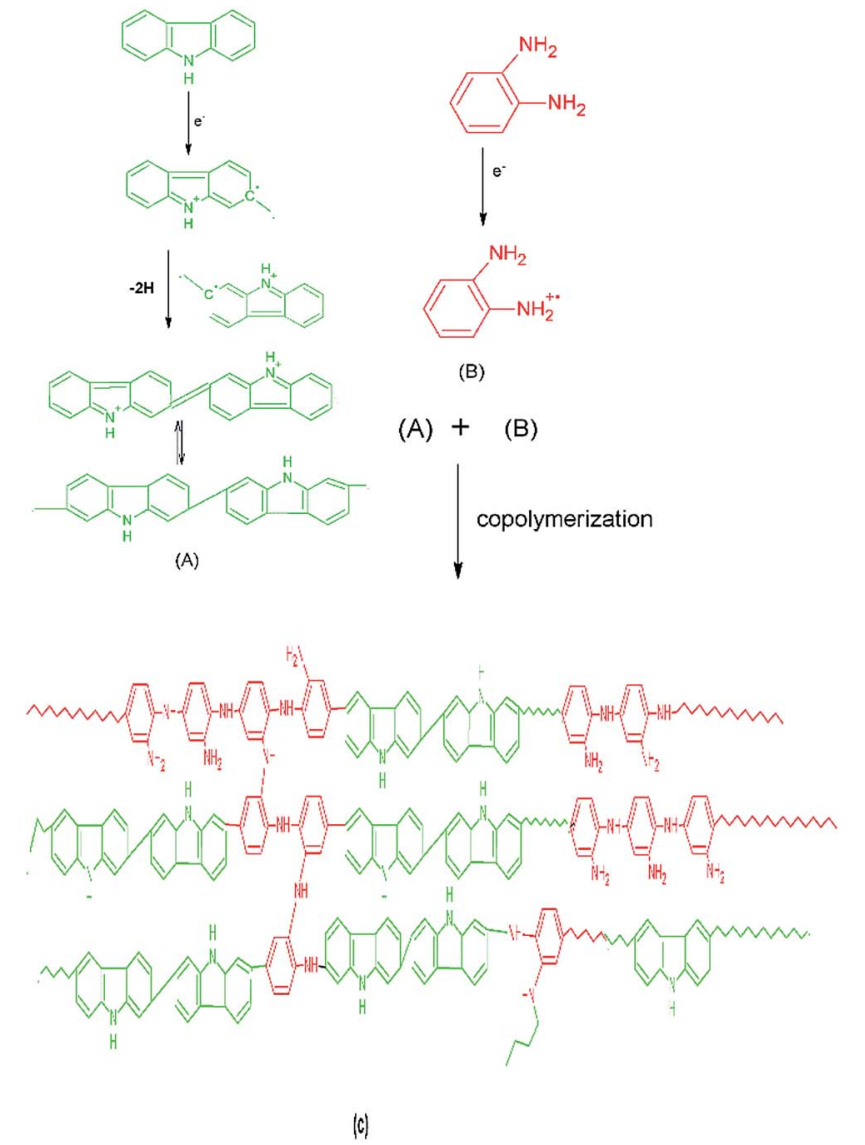

Scheme 1 Copolymerization scheme of PCz with POPD showing the reaction between carbazole dimer $(\mathrm{A})$ with free radicals of $O$-phenylenediamine (B) to form a random copolymer (C).

The scheme of polymerization, Scheme 1, is based on the results obtained from decomposition kinetics which is discussed in later section. Carbazole free radical is highly unstable and shows the tendency to form dimers rapidly which has been well documented in literature. ${ }^{32,33}$ Hence, the copolymerization is scheme is shown to proceed via the reaction of carbazole dimer with $o$-phenylenediamine, Scheme 1.

It was noticed that the calculated and observed \% $\mathrm{C}$ in the copolymers differed by a fairly noticeable margin, except copolymer PCz : POPD-90 : 10, \% $\mathrm{H}$ values differed by $1 \%$, but $\% N$ values varied between $5-10 \%$ (given in ESI Table S3 $\dagger$ ). Such a noticeable error resulted from some determinational discrepancy. The monomer ratio in the copolymers as determined from CHN varied significantly from the monomer feed ratio particularly in the first and last copolymer samples. This indicated change in the monomer reactivity ratio during the course of polymerization. The reactivity ratios, $r_{1}$ and $r_{2}$, of these copolymers were calculated, employing Fineman-Ross method $^{34}$ based on CHN values.

The ${ }^{1} \mathrm{H}-\mathrm{NMR}$ spectra of POPD (given in ESI Fig. S1†) revealed $\mathrm{NH}$ proton at $\delta=6.8-7.9 \mathrm{ppm}$, and skeletal $\mathrm{NH}$ proton of $\mathrm{PCz}$ showed peak from $\delta=6.9-8.11 \mathrm{ppm}$. The overlap of aromatic protons peak of two monomers hinders the assignments of individual peaks in this region to individual monomers. Iraqi et al. ${ }^{35}$ attributed the peaks at $\delta=8.15 \mathrm{ppm}(2 \mathrm{H})$ and $7.36 \mathrm{ppm}$ $(2 \mathrm{H})$ to 4,5 and 3, 6 protons of $\mathrm{PCz}$ which were also observed in our case and the peak at $\delta=7.6 \mathrm{ppm}(2 \mathrm{H})$ was related to 1,8 protons. The above data in our case showed 2-7 linkages in $\mathrm{PCz}$ and its copolymer. Intrinsic viscosities of homopolymers were observed to be 0.16 and 0.35 respectively for $\mathrm{PCz}$ and POPD. The viscosity average molar mass calculated using Mark-Houwink equation: $[\eta]=K M_{\mathrm{v}}{ }^{a}$, where, $\eta$ is the intrinsic viscosity, $\eta=$ $1.95 \times 10^{-6} M_{\mathrm{v}}{ }^{21} M_{\mathrm{v}}$ is molecular weight; $K$ and $a$ are constants for a particular polymer-solvent system. $M_{\mathrm{v}}$ was found to be 4320 for PCz and 6583 for POPD. The intrinsic viscosity of the copolymers varied between the above two limits. These values indicate neither very high nor low molar masses. Li et al. ${ }^{36}$ have found that when intrinsic viscosity varied between $0.14-0.33$, $M_{\mathrm{n}}$ of poly (ethylaniline-co-anisidine) varied between $2120-5470$ daltons. We have also calculated the molar mass of the copolymers on the basis of the foregoing equation. The monomer reactivity ratios were obtained from the molar feed ratio of $\mathrm{PCz}$ and POPD in each copolymer composition, as determined from CHN results, Table 1. Employing the Fineman-Ross (FR) equation, ${ }^{34}$ the values of $r_{1}$ and $r_{2}$, were found as 0.417 and 0.312 , (given in ESI Fig. $\mathrm{S} 2 \dagger$ ), which revealed random copolymerisation. Table 1 also revealed that in the initial composition containing more carbazole monomer, i.e., PCz : POPD-90 : 10, $r_{1}$ appears to be quite high indicating $\mathrm{Cz}$ polymerizes in much higher proportion than o-phenylenediamine but for the composition around $\mathrm{PCz}$ : POPD-10:90 containing more $o$ -

Table 1 Molar feed ratios determined by ${ }^{1} \mathrm{H}-\mathrm{NMR}$ and Fineman Ross parameters

\begin{tabular}{|c|c|c|c|c|c|c|c|}
\hline \multicolumn{2}{|c|}{$\begin{array}{l}\text { Molar feed ratio of } \\
\text { monomer }\end{array}$} & \multirow[b]{2}{*}{$f=f_{1} / f_{2}$} & \multicolumn{2}{|c|}{$\begin{array}{l}\text { Molar ratio as determined } \\
\text { by }{ }^{1} \mathrm{H}-\mathrm{NMR}\end{array}$} & \multirow[b]{2}{*}{$F=F_{1} / \mathrm{F}_{2}$} & \multicolumn{2}{|c|}{ Fineman Ross parameters } \\
\hline$f_{1}$ & $f_{2}$ & & $F_{1}$ & $F_{2}$ & & $f(F-1) / F$ & $f^{2} / F$ \\
\hline 0.10 & 0.9 & 0.11 & 0.35 & 0.65 & 0.54 & 0.094 & 0.022 \\
\hline 0.3 & 0.7 & 0.43 & 0.40 & 0.60 & 0.66 & 0.22 & 0.280 \\
\hline 0.4 & 0.6 & 0.66 & 0.45 & 0.55 & 0.82 & 0.145 & 0.532 \\
\hline 0.7 & 0.3 & 2.3 & 0.65 & 0.35 & 1.85 & 1.05 & 2.859 \\
\hline 0.9 & 0.1 & 9 & 0.75 & 0.25 & 3.0 & 6.0 & 27 \\
\hline
\end{tabular}


Table 2 Oxidation and reduction peaks of homopolymers and copolymers obtained from the cyclic voltammetry studies

\begin{tabular}{|c|c|c|c|c|}
\hline Sample & $E_{\mathrm{p}-\mathrm{ox}}(\mathrm{V})$ & $I_{\mathrm{p}-\mathrm{ox}}(\mu \mathrm{A})$ & $E_{\mathrm{p} \text {-red }}(\mathrm{V})$ & $I_{\mathrm{p} \text {-red }}(\mu \mathrm{A})$ \\
\hline Pure POPD & $0.13(\mathrm{I})$ & 18(I) & $-0.05,0.15(\mathrm{I})$ & $50(\mathrm{I})$ \\
\hline Pure $\mathrm{PCz}$ & 0.3 (II) & $10(\mathrm{II})$ & $0.5(\mathrm{II})$ & $10(\mathrm{II})$ \\
\hline PCz-POPD: $40: 60$ & $0.15(\mathrm{I}), 0.35(\mathrm{II})$ & 22(I), 11(II) & $-0.025(\mathrm{I}), 0.23(\mathrm{II})$ & $8(\mathrm{I}), 5(\mathrm{II})$ \\
\hline $\mathrm{PCz}:$ POPD-60 : 40 & $0.18(\mathrm{I}), 0.38(\mathrm{II})$ & $6(\mathrm{I}), 3(\mathrm{II})$ & $-0.025(\mathrm{I}), 0.35(\mathrm{II})$ & $2(\mathrm{I}), 1.5(\mathrm{II})$ \\
\hline PCz : POPD: $70: 30$ & $0.17(\mathrm{I}), 0.35(\mathrm{II})$ & $3.6(\mathrm{I}), 2.5(\mathrm{II})$ & $-0.02(\mathrm{I}), 0.2(\mathrm{II})$ & $2.9(\mathrm{I}), 2.5(\mathrm{II})$ \\
\hline
\end{tabular}

phenylenediamine monomers, $r_{2}$ shows higher extent of polymerisation of $o$-phenylenediamine. In other composition range, polymerisation rate of $\mathrm{Cz}$ is little lower than OPD. It has been reported by several authors that carbazole rapidly forms dimers and hence when the molar ratio of carbazole is high, PCz chains are homopolymerized and few POPD units are attached. But when the molar ratio of $o$-phenyenediamine is increased, the extent of homo-polymerization of POPD becomes higher as compared to PCz. However, when the molar ratio is equal, the tendency to copolymerize becomes higher. This observation is also confirmed by the molar ratios determined from ${ }^{1} \mathrm{H}-\mathrm{NMR}$ results.

Table 2 shows the redox potential obtained from CV curves (given in ESI Fig. S3†) of PCz, POPD and its copolymers. The $E_{\mathrm{p}-\mathrm{ox}}$, potential at the oxidation peak of POPD was noticed to be 0.13 volt and $E_{\text {p-red }}$, potential at the reduction peak of POPD as -0.5 and 0.15 volt, the corresponding current densities, $I_{\mathrm{p}-\mathrm{ox}}$, and $I_{\mathrm{p} \text {-red }}$ being $18 \mu \mathrm{A}$ and $50 \mu \mathrm{A}$. Likewise the $E_{\mathrm{p}-\text { ox }}, E_{\mathrm{p}-\text { red }}, I_{\mathrm{p}-\mathrm{ox}}$, and $I_{\mathrm{p} \text {-red }}$ values of $\mathrm{PCz}$ were respectively found as 0.3 volt, 0.5 volt and $10 \mu \mathrm{A}, 10 \mu \mathrm{A}$. Inzlett ${ }^{37}$ has shown that the $E_{\mathrm{p}-\mathrm{ox}}$ of $^{2+} / \mathrm{D}$ or $\mathrm{P}^{+} / \mathrm{P}$, carbazole dimer and polymer $=0.33 \mathrm{~V}$ which matches with our result. Copolymers of POPD and $\mathrm{PCz}$ showed an increase in $E_{\mathrm{p} \text {-ox }}$ of both the components and a decrease in $E_{\mathrm{p}-\text { red }}$ of both the components. Moreover the second reduction potential of POPD, $E_{\mathrm{p} \text {-red }}, 0.15$ volt, did not show up in CV of all copolymer composition. $I_{\mathrm{p}-\mathrm{ox}} \mathrm{POPD}$ and $\mathrm{PCz}$ in copolymers where the POPD is more than 50\%, is comparable with those of their pure forms. All the above observations clearly confirm the copolymer formation. In the copolymers with $\operatorname{POPD}(\mathrm{I})$ being less than $50 \%, E_{\mathrm{p}-\mathrm{ox}}$, and $E_{\mathrm{p} \text {-red }}$, of POPD(I), and PCz(II), behave in the same way, but $I_{\mathrm{p}-\mathrm{ox}}$ of components (I) and (II) decrease drastically, while the $I_{\mathrm{p}-\mathrm{red}}$ of both the components also decrease. It indicates that oxidation of components (I) and (II) becomes sluggish in the above copolymers.

The FT-IR spectra of homopolymers and copolymers were taken and are given in ESI, Fig. S4. $\dagger$ The band at $3419 \mathrm{~cm}^{-1}$ was attributed to - $\mathrm{NH}$ - group in $\mathrm{PCz}$, while in POPD, it was observed at $3394 \mathrm{~cm}^{-1}$ and in between $3394-3419 \mathrm{~cm}^{-1}$ for the copolymers which indicated the presence of secondary amino groups $(-\mathrm{NH}-)$ in copolymers. The imine stretching peaks for $\mathrm{PCz}$ and POPD were observed to be around $1606 \mathrm{~cm}^{-1}, 1636 \mathrm{~cm}^{-1}$ respectively. The peak of quinonoid units in $\mathrm{PCz}$ was noticed at $1512 \mathrm{~cm}^{-1}$ while for POPD, it was observed at $1532 \mathrm{~cm}^{-1}$ and the absorption intensities of above were found to be $0.13,0.52$ respectively. The peak at $1452 \mathrm{~cm}^{-1}$ was attributed to benzenoid form in PCz while in POPD, this peak was observed at 1480 $\mathrm{cm}^{-1}$ and absorption intensities of above were found to be 0.36 , 0.25 respectively. In this way, the benzenoid to quinonoid ratio $(B / Q)$ was calculated as $(0.36 / 0.13)=2.76$ for $\mathrm{PCz}$, and $(0.25 /$ $0.52)=0.48$ for POPD demonstrating more benzenoid units in $\mathrm{PCz}$ and larger number of quinonoid units POPD. The absorption peak at $1452-1533 \mathrm{~cm}^{-1}$ was associated with benzenoid ring stretching vibration which shifted to a higher wave number with increasing $o$-phenylenediamine units. In copolymers, the quinonoid peak possessed higher intensity as compared to that of benzenoid. In copolymers of different ratios $(90: 10,70: 30,60: 40,50: 50,40: 60,30: 70,10: 90)$ with respect to $\mathrm{PCz}$ and $\mathrm{POPD}$, the ratio of absorption intensity of benzenoid to quinonoid was noticed to be $0.750,0.69,0.82,0.8$, $0.64,0.746,1.02$ respectively. Since in the copolymers, the ratio was determined to be below 1.0, the quinonoid units appeared to be slightly higher than benzenoid ones. Both quinonoid and benzenoid forms were present in homopolymer and copolymer chains indicating their conducting nature. The value of $\int a d \bar{v}$ of $\mathrm{NH}$ region of $\mathrm{PCz}\left(51.10 \mathrm{~cm}^{-2}\right)$ was lower than that of POPD $\left(58.34 \mathrm{~cm}^{-2}\right)$. There was noticeable increase in these values as the loading of POPD increased in the copolymers.

\section{Influence of copolymerization on morphology confirmed by XRD and TEM studies}

XRD profile of homopolymer $\mathrm{PCz}$, Fig. 1(a), showed well pronounced peaks at $2 \theta=8.5^{\circ}, 9.2^{\circ}, 19.7^{\circ}, 19.9^{\circ}, 23.4^{\circ}, 28.2^{\circ}$ indicating crystalline structure corresponding to the planes (020), (010), (100), (110) and (011) which were determined on the basis of pseudo orthorhombic lattice. ${ }^{21}$ The homopolymer POPD, Fig. 1(b), similarly revealed peaks at $2 \theta=9.22^{\circ}, 18.5^{\circ}$, $19.78^{\circ}, 23.5^{\circ}$ and $28.08^{\circ}$, with only the first peak being pronounced. It also showed crystalline state with limited planes (010), (110) and (011). The copolymers showed peaks of both the homopolymers with slight variation in the positions of some of the peaks along with omission of peaks noticed at $10.76^{\circ}$ and $16.66^{\circ}$ peaks correlated to POPD. All the peaks are found to be well formed and confirmed crystalline state of the copolymers. ${ }^{21}$ It was observed that the copolymers PCz:POPD-90:10, PCz : POPD-70 : 30, PCz : POPD-60 : 40, Fig. 1(c)-(e), showed the above peaks, with low intensity, except the peak at $2 \theta=$ $9.36^{\circ}$ indicating that the number of polymer chains in the corresponding planes were low. But the copolymers PCz : POPD50 : 50, PCz : POPD-40 : 60, PCz : POPD-30 : 70, PCz : POPD10 : 90, Fig. 1(f)-(i), with POPD ratio $50 \%$ and higher showed 

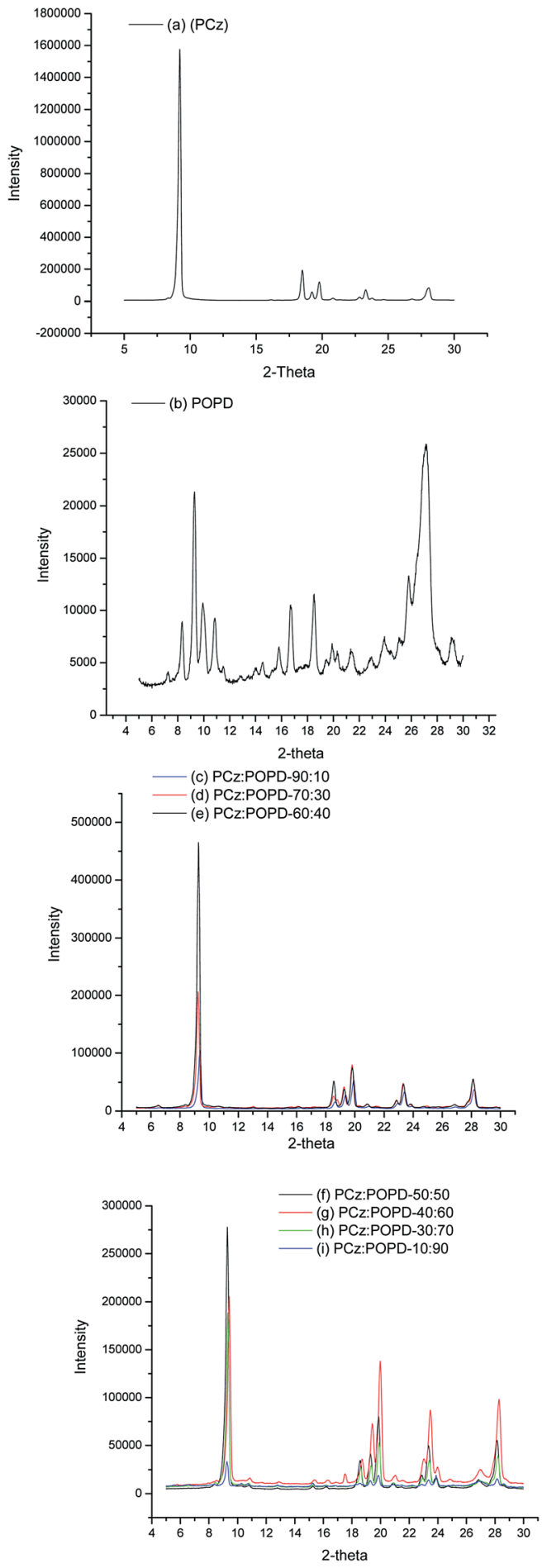

Fig. 1 XRD profiles of (a) PCz, (b) POPD, (c) PCz : POPD-90:10, (d) PCz : POPD-70 : 30, (e) PCz : POPD-60 : 40, (f) PCz : POPD-50 : 50, (g) PCz : POPD-40:60, (h) PCz : POPD-30: 70 and (i) PCz : POPD$10: 90$.

high peak intensity which indicated relatively larger number of POPD chains in the corresponding planes.

The TEM of PCz, Fig. 2(a), revealed spherical particles. The particle size was found to be $200 \mathrm{~nm}$. The TEM of POPD, Fig. 2(b), showed fibrillar morphology. The copolymer
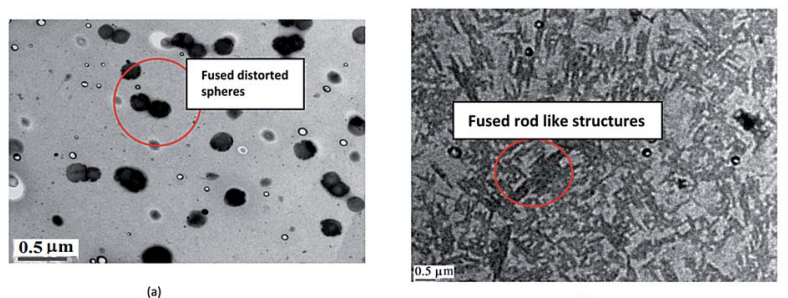

(b)
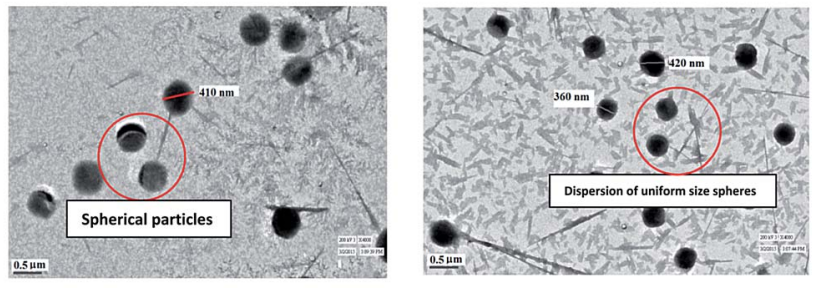

(c)
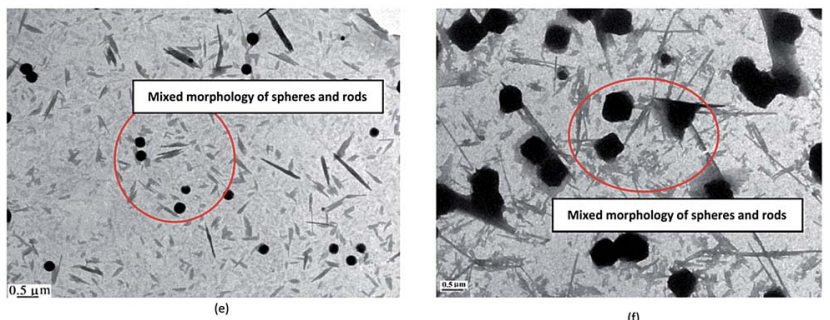

Fig. 2 TEM of (a) PCz, (b) POPD, (c) PCz: POPD-90:10, (d) PCz : POPD-70 : 30, (e) PCz : POPD-50 : 50, (f) PCz : POPD-30 : 70.

composition $\mathrm{PCz}$ : POPD-90 : 10, Fig. 2(c), revealed predominantly spherical particles matching with the $\mathrm{PCz}$ particles. The composition PCz: POPD-70:30, Fig. 2(d), showed spherical particles, in case of later, the particles appeared smaller. Some spindle shaped particles were also seen which resembled the morphology found in POPD. The morphology of copolymer PCz : POPD-50:50, Fig. 2(e), showed mixed morphology of POPD rod shaped particles along with PCz spheres which were observed to be uniformly scattered. Upon increasing the loading of POPD, PCz : POPD-30 : 70, Fig. 2(f), the PCz particles were observed to be fused together and elongated POPD rods were formed. The morphology of the mixture of POPD and PCz particles (given in ESI Fig. S5 $\dagger$ ) was found to be quite different from the ones obtained for the copolymers. Dense black aggregates of $\mathrm{PCz}$ particles were noticed while POPD particles were found to be randomly dispersed exhibiting highly distorted morphology. The difference in the morphology of the mixture and the copolymers confirmed random copolymerization of PCz with POPD and the copolymers were seen to adopt the morphology of $\mathrm{PCz}$ or POPD depending upon the composition. ${ }^{21}$

\section{Influence of copolymerization on the UV-visible and fluorescent properties}

The UV-visible spectra of PCz, POPD and its copolymers (taken in NMP) are shown in Fig. 3. Peaks for PCz were observed at $293 \mathrm{~nm}$ and $336 \mathrm{~nm}$, while for POPD, they were observed at $280 \mathrm{~nm}$ as well as $440 \mathrm{~nm}$. The peaks in the UV range were 


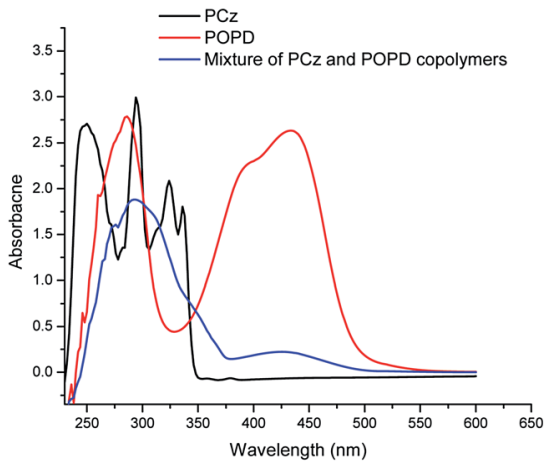

(a)

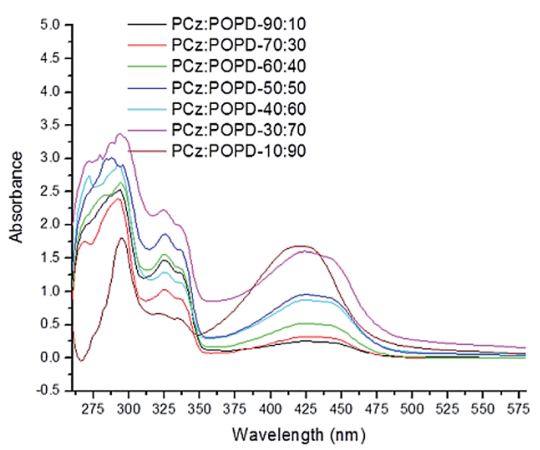

(b)

Fig. 3 UV-visible spectra of (a) PCz, POPD (b) PCz: POPD copolymers.

assigned to $\pi-\pi^{*}$ transitions. ${ }^{21,28}$ The peak at $425 \mathrm{~nm}$ was correlated to polaron formation which indicated the conducting state of the polymer and the transition was associated with the phenazine ring which is conjugated to two lone pairs of electrons on nitrogen atom of the $\mathrm{NH}_{2}$ groups. The spectra of the mixture of PCz and POPD showed a broad hump at $300 \mathrm{~nm}$ and a diffuse hump around $425 \mathrm{~nm}$. Interestingly, the spectra of copolymers were observed to be different from the spectra of the mixture of the two polymers. All the copolymers showed peaks corresponding to both POPD and $\mathrm{PCz}$ and their intensities were found to vary with the feed ratio, which confirmed that even during copolymerization, their individual polaronic states were retained. Pure POPD revealed a broad hump spanning from 400-450 nm while in the copolymer, it showed a bathochromic shift of $15 \mathrm{~nm}$. It appeared that some of the electrons on nitrogen were pulled in the phenylene ring. The intensity of the $425 \mathrm{~nm}$ peak in copolymer was the lowest for PCz: POPD90 : 10 (0.2 a.u.) and highest for PCz : POPD-10 : 90 (1.5 a.u.), but the later was much lower than that of pure POPD (2.5 a.u.). This may have been caused by reduction in HOMO-LUMO overlap of the involved orbital in the copolymer. The peak corresponding to POPD in the copolymer varied linearly with the feed ratio. $\mathrm{PCz}$ present in the copolymer showed peaks at $290 \mathrm{~nm}$ and $325 \mathrm{~nm}$.

Highest intensity peak of $290 \mathrm{~nm}$ was noticed for the copolymer in which $\mathrm{PCz}$ ratio was second lowest $30: 70$, followed by $50: 50,60: 40,70: 30$. The peak was correlated to $\mathrm{n}-\pi^{*}$ transition. Because the orientation of pyrrole moiety is upward or downward, transition dipole moment will also adopt the same orientation. At low concentration, the pyrrole moiety in $\mathrm{PCz}$ molecules adopts the same orientation, due to the absence of torsional strain and hence their transition dipole moment as well as intensity will be higher. However, when ratio of $\mathrm{PCz}$ is higher, the pyrrole moieties in PCz molecules adopt opposite orientation to avoid torsional strain and attain a nonplanar configuration. Hence, the dipole moments cancel each other and show lower intensity. As the number of carbazole units increase, the extent of conjugation increases and torsional strain is experienced in a planar conformation. The pyrrole moieties change their orientation to minimize torsional strain and are therefore arranged in a nonplanar conformation. This argument matches with the structure of copolymer depicted in Scheme 1. The molar extinction coefficient and the oscillator strength values for the homopolymers were found to be higher than its copolymers because of the structural variation in the two cases. The molar extinction coefficient and the oscillator strength values of $\mathrm{PCz}$ and $\mathrm{POPD}$, respectively decreased and increased as the amount of the two monomers varied in the copolymer, Table 3 . Structural changes in the copolymers also contribute to the increase as well as decrease of molar extinction coefficient values. For PCz: POPD-90:10, the molar extinction coefficient value $\left(\dot{\varepsilon}_{\mathrm{m}}\right)$ for $\mathrm{PCz}$ was found to be 6967.74 while for POPD, it was calculated to be 838.71. For PCz : POPD$70: 30, \dot{\varepsilon}_{\mathrm{m}}$ value for PCz decreased to 5411.7 and that of POPD increased to 1235.29. Likewise, for copolymer PCz: POPD$50: 50, \dot{\varepsilon}_{\mathrm{m}}$ value of $\mathrm{PCz}$ decreased to 5578.95 with respect to pure PCz while $\dot{\varepsilon}_{\mathrm{m}}$ value of POPD increased to 3105.26 with respect to pure POPD. Same trend was found for $\mathrm{PCz}$ : POPD $10: 90$, where $\dot{\varepsilon}_{\mathrm{m}}$ value for $\mathrm{PCz}$ decreased to 3409.09 , and for POPD increased to 5909.09. From the copolymer composition, PCz : POPD-90:10 up to the copolymer composition, PCz : POPD-60 : 40, the oscillator strength at $\lambda_{\max }=425 \mathrm{~nm}$ for

Table 3 Values of molar extinction coefficient and oscillator strength calculated for PCz, POPD and their copolymers

\begin{tabular}{llll}
\hline Sample & $\begin{array}{l}\lambda_{\max } \\
(\mathrm{nm})\end{array}$ & $\begin{array}{l}\text { Molar extinction } \\
\text { coefficient }\end{array}$ & $\begin{array}{l}\text { Oscillator } \\
\text { strength }\end{array}$ \\
\hline PCz & 325 & 8857.14 & 0.12 \\
POPD & 425 & 9782.61 & 0.14 \\
PCz : POPD $(90: 10)$ & 325 & 6967.74 & 0.10 \\
& 425 & 838.71 & 0.02 \\
PCz : POPD $(70: 30)$ & 325 & 5411.76 & 0.07 \\
& 425 & 1235.29 & 0.02 \\
PCz : POPD $(60: 40)$ & 325 & 7111.11 & 0.04 \\
& 425 & 1722.22 & 0.03 \\
PCz : POPD $(50: 50)$ & 325 & 5578.95 & 0.03 \\
& 425 & 3105.26 & 0.06 \\
PCz : POPD $(40: 60)$ & 325 & 4564.10 & 0.03 \\
& 425 & 2820.51 & 0.06 \\
PCz : POPD $(30: 70)$ & 325 & 5951.22 & 0.02 \\
& 425 & 3707.32 & 0.08 \\
PCz : POPD $(10: 90)$ & 325 & 3409.09 & 0.01 \\
& 425 & 5909.09 & 0.13
\end{tabular}


POPD varied between $0.02-0.03$ while from the copolymer composition, $\mathrm{PCz}$ : POPD-40: 60 up to the copolymer composition PCz : POPD-10 : 90, it varied between 0.6-0.13. The relatively large increase in oscillator strength for the later compositions indicated structural changes in the copolymer showing the formation of two copolymer complexions.

The fluorescence spectra of $\mathrm{PCz}, \mathrm{POPD}$ and their various copolymers dissolved in NMP and THF were recorded and are given in Fig. 4. The samples were excited at $400 \mathrm{~nm}$ and emission spectra were recorded from 450-700 $\mathrm{nm}$. The emission spectrum of pure PCz and NMP, Fig. 4(a), were also taken which revealed no peak in this region. For the copolymer PCz : POPD$90: 10$ and PCz:POPD-70:30 in NMP, a broad peak was noticed at $490 \mathrm{~nm}$ which was attributed to $S_{1} \rightarrow S_{0}$ transition. The broadness of the peak was related to intense hydrogen bonding of the two copolymers containing higher PCz content. With the increase in the number of POPD chains, the intensity of this peak appeared to increase and show a shift towards $520 \mathrm{~nm}$. The emission spectra of pure POPD revealed highest intensity peak at $525 \mathrm{~nm}$. The emission spectra for pure THF and pure $\mathrm{PCz}$ in THF also revealed the same behaviour. No emission peak of THF was observed upon excitation at $400 \mathrm{~nm}$, Fig. 4(b). With the increase in the POPD content, the emission intensity of the peak corresponding to $525 \mathrm{~nm}$ increased progressively. The intensity of the $525 \mathrm{~nm}$ peak was observed to increase in both NMP as well as THF with the increase in the

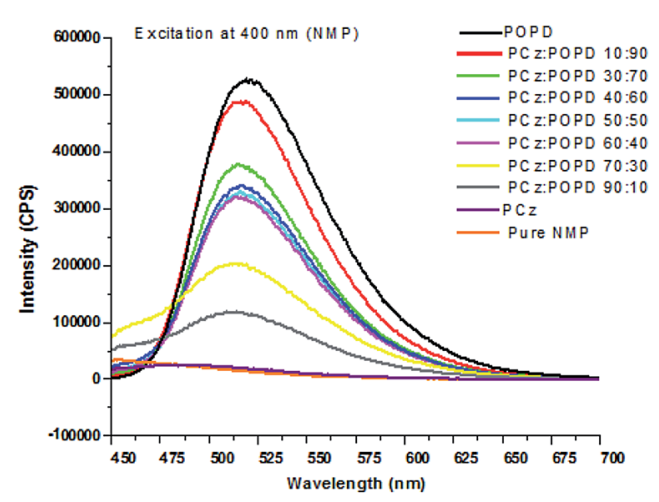

(a)

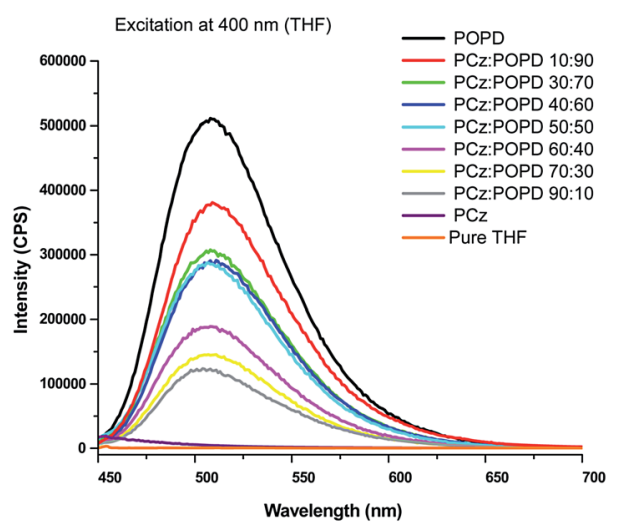

(b)

Fig. 4 Fluorescence spectra of PCz, POPD and their copolymers in (a) NMP (b) THF.
Table 4 Quantum yield values for homopolymers and copolymers taken in solution (NMP as solvent)

\begin{tabular}{llll}
\hline & $\begin{array}{l}\lambda_{\text {max }} \\
(\mathrm{nm})\end{array}$ & $\begin{array}{l}\text { Integrated area } \\
\left(I_{\text {samp }}\right)\end{array}$ & $\begin{array}{l}\text { Quantum yield } \\
(\Phi)\end{array}$ \\
\hline PCz & 410 & $3.57 \times 10^{8}$ & 0.25 \\
POPD & 525 & $1.42 \times 10^{9}$ & 0.40 \\
PCz : POPD $(90: 10)$ & 500 & $2.79 \times 10^{8}$ & 0.24 \\
PCz : POPD $(70: 30)$ & 500 & $5.03 \times 10^{8}$ & 0.27 \\
PCz : POPD $(60: 40)$ & 520 & $8.48 \times 10^{8}$ & 0.31 \\
PCz : POPD $(50: 50)$ & 520 & $8.08 \times 10^{8}$ & 0.30 \\
PCz : POPD $(40: 60)$ & 520 & $9.51 \times 10^{8}$ & 0.32 \\
PCz : POPD $(30: 70)$ & 520 & $8.65 \times 10^{8}$ & 0.33 \\
PCz : POPD (10: 90$)$ & 520 & $1.26 \times 10^{9}$ & 0.37 \\
& & &
\end{tabular}

POPD content. The intensity of the emission peak for the copolymer composition PCz : POPD-10 : 90 was observed to be $510000 \mathrm{cps}$ in NMP and THF. The copolymer PCz: POPD$30: 70$ revealed an emission intensity of $350000 \mathrm{cps}$ and $310000 \mathrm{cps}$ in NMP and THF respectively. But for the composition PCz : POPD-40 : 60 and PCz : POPD-50 : 50, the emission intensities were noticed to be $320000 \mathrm{cps}$ in NMP and 280000 and 140000 cps in THF respectively. The copolymer PCz : POPD-70 : 30 revealed an emission intensity of 210000

Table 5 Activation energy obtained by $\mathrm{F}-\mathrm{W}-\mathrm{O}$ method, Friedman method and Vyazokovin method

\begin{tabular}{|c|c|c|c|c|}
\hline \multirow[b]{2}{*}{$\begin{array}{l}\text { Copolymers } \\
\text { PCz : POPD }\end{array}$} & \multirow{2}{*}{$\begin{array}{l}\text { Degree of } \\
\text { conversion } \\
(\alpha)(\%)\end{array}$} & \multicolumn{3}{|c|}{ Activation energy $\left(E_{\mathrm{a}}\right)\left(\mathrm{kJ} \mathrm{mol}^{-1}\right)$} \\
\hline & & $\begin{array}{l}\mathrm{F}-\mathrm{W}-\mathrm{O} \\
\text { method }\end{array}$ & $\begin{array}{l}\text { Friedman } \\
\text { method }\end{array}$ & $\begin{array}{l}\text { Vyazokovin } \\
\text { method }\end{array}$ \\
\hline \multirow[t]{4}{*}{$90: 10$} & 10 & 38.8 & 28.42 & 34.93 \\
\hline & 20 & 52.75 & 43.52 & 45.76 \\
\hline & 30 & 67.0 & 59.96 & 57.90 \\
\hline & 40 & 69.86 & 65.36 & 62.2 \\
\hline Average & & 57.11 & 49.3 & 50.21 \\
\hline \multirow[t]{4}{*}{$70: 30$} & 10 & 71.42 & 60.35 & 65.53 \\
\hline & 20 & 67.55 & 64.80 & 68.09 \\
\hline & 30 & 64.75 & 59.70 & 62.06 \\
\hline & 40 & 64.95 & 59.71 & 61.93 \\
\hline Average & & 61.67 & 61.14 & 64.4 \\
\hline \multirow[t]{4}{*}{$60: 40$} & 10 & 71.83 & 60.35 & 62.53 \\
\hline & 20 & 71.83 & 64.89 & 68.09 \\
\hline & 30 & 66.97 & 59.71 & 62.06 \\
\hline & 40 & 66.97 & 59.71 & 61.93 \\
\hline Average & & 69.4 & 61.16 & 63.65 \\
\hline \multirow[t]{4}{*}{$40: 60$} & 10 & 135.76 & 132.02 & 135.27 \\
\hline & 20 & 127.87 & 124.71 & 127.12 \\
\hline & 30 & 114.29 & 110.42 & 11.28 \\
\hline & 40 & 135.77 & 132.87 & 133.39 \\
\hline Average & & 128.42 & 125.0 & 126.7 \\
\hline \multirow[t]{3}{*}{$30: 70$} & 10 & 77.17 & 66.09 & 69.20 \\
\hline & 20 & 53.43 & 46.65 & 47.60 \\
\hline & 30 & 89.34 & 81.85 & 84.60 \\
\hline Average & & 73.85 & 65.85 & 67.67 \\
\hline \multirow[t]{3}{*}{$10: 90$} & 20 & 280.25 & 284.92 & 285.27 \\
\hline & 30 & 99.53 & 94.33 & 93.55 \\
\hline & 40 & 41.29 & 37.08 & 36.45 \\
\hline Average & & 140.27 & 138.77 & 148.2 \\
\hline
\end{tabular}


cps in NMP and 150000 in THF respectively. The solvent was therefore found to play little role in the favorable geometrical orientation of HOMO and LUMO orbitals. However the copolymerization was found to push the emission towards near infrared region. Quantum yield $(\Phi)$ was calculated by taking Rhodamine B as reference and the values are shown in Table 5 for NMP. The integrated area, $\int a d \bar{v}$, of the peak $\approx 525 \mathrm{~nm}$ of POPD was calculated to be $1.42 \times 10^{9}$. In the copolymer PCz : POPD-90 : 10, $\int a d \bar{v}$ of the above peak was found to be low, $2.79 \times 10^{8}$. As the ratio of POPD increased in case of PCz : POPD-70 : 30, PCz : POPD-60 : 40, $\int a d \bar{v}$ increased to 5.03 $\times 10^{8}$ and $8.48 \times 10^{8}$ respectively. Upon further increasing the POPD ratio to $\mathrm{PCz}:$ POPD-40:60, PCz : POPD-30 : 70, PCz : POPD-10: 90, $\int a d \bar{v}$ finally increased to $9.51 \times 10^{8}$ and
$8.65 \times 10^{8}$ and $1.26 \times 10^{9}$. Quantum yield of POPD was found to be 0.24 in copolymer PCz : POPD-90:10. The quantum yield values were noticed to her higher for the copolymers containing higher POPD content. Similar trend of variation of quantum yield was observed in THF solution (Table 4).

\section{Thermal behavior and decomposition kinetics study of copolymers}

TGA-DTG curves for the decomposition of different compositions of PCz:POPD copolymers are given in Fig. 5(a)-(i). Copolymers of composition PCz: POPD-10:90 and PCz: POPD$30: 70$, Fig. 5(c) and (d), showed four DTG peaks each. PCz : POPD-10: 90 showed DTG peaks at $90{ }^{\circ} \mathrm{C}$ which was attributed to the evaporation of solvent and water. The second peak at $225{ }^{\circ} \mathrm{C}$ was correlated to decomposition of $\mathrm{PCz}$ fragments in the copolymer. The peak at $310{ }^{\circ} \mathrm{C}$ arose due to the degradation of POPD while the peak at $475{ }^{\circ} \mathrm{C}$ was attributed to

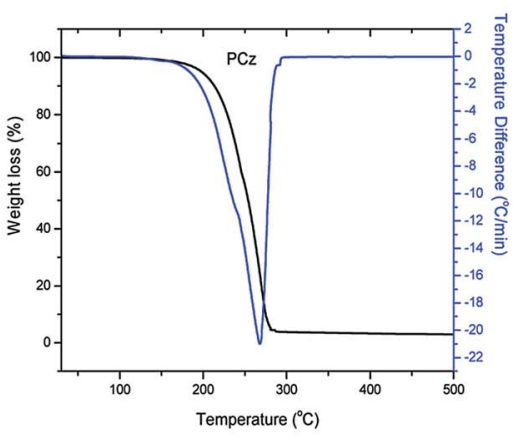

(a)

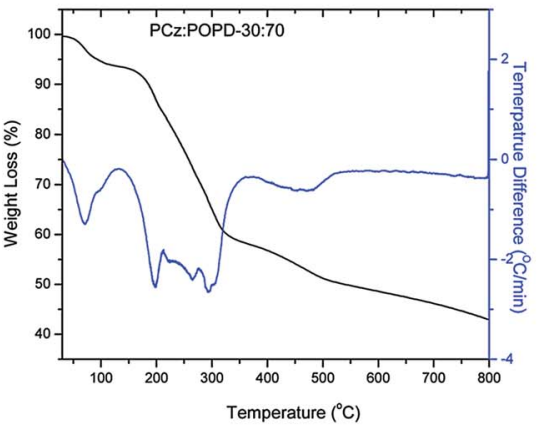

(d)

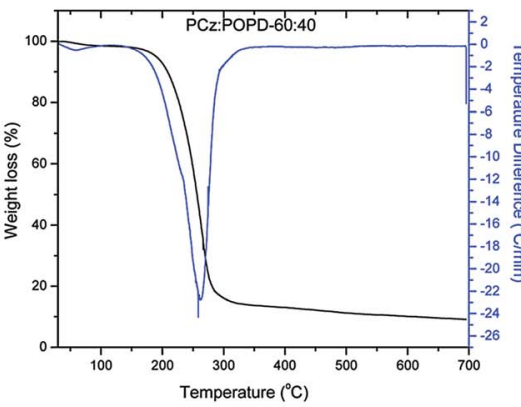

(g)

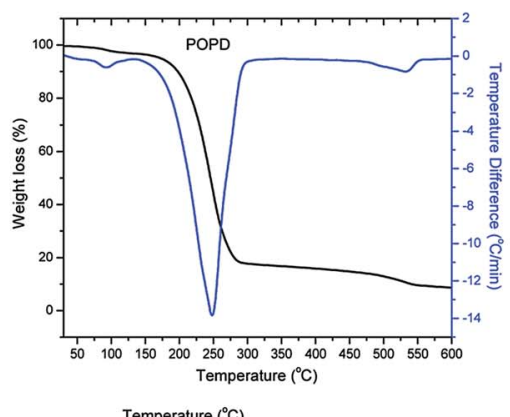

(b)

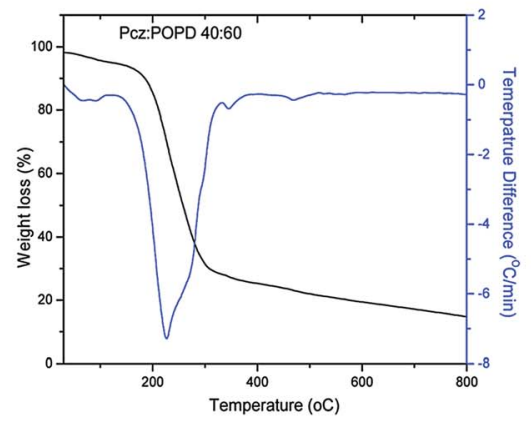

(e)

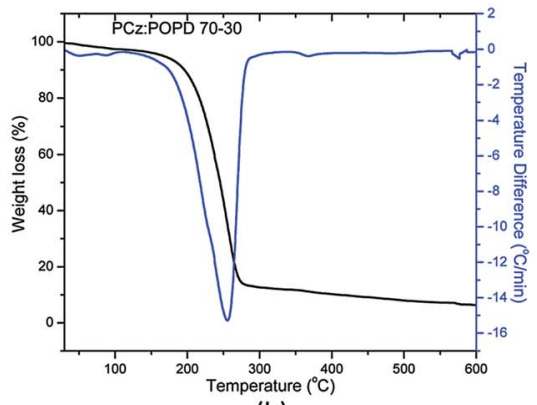

(h)

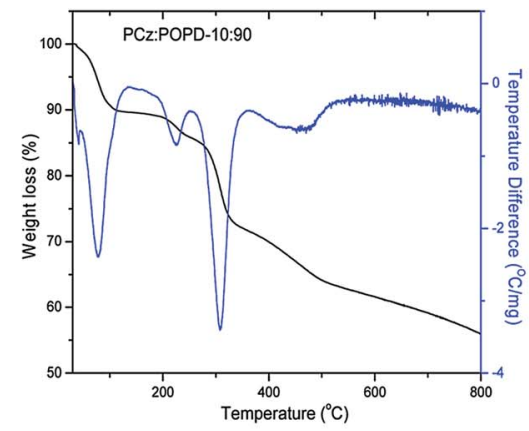

(c)

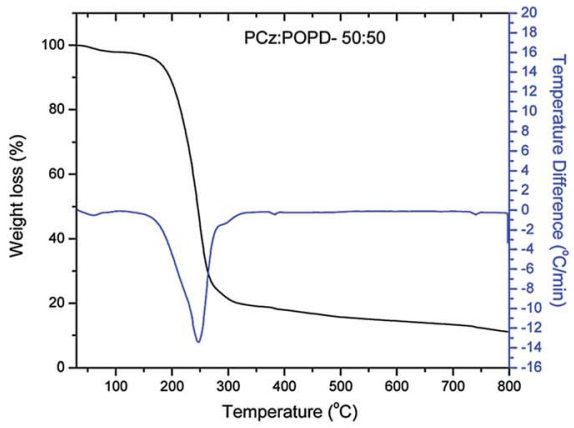

(f)

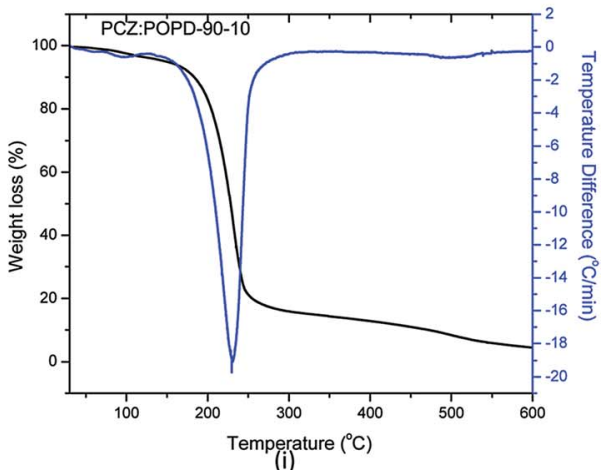

Fig. 5 TGA-DTG plots of (a) PCz, (b) POPD (c) PCz: POPD-10: 90 (d) PCz : POPD-30 : 70, (e) PCz : POPD-40: 60, (f) PCz : POPD-50 : 50, (g) PCz : POPD-60 : 40, (h) PCz : POPD-70 : 30, (i) PCz : POPD-90 : 10. 
the linkage between $\mathrm{PCz}$ and POPD. The char value in this case was found to be $52 \%$ which seems to be fairly high. The copolymer PCz : POPD-30 : 70 also showed one solvent evaporation peak along with three decomposition peaks at $60{ }^{\circ} \mathrm{C}$, $200{ }^{\circ} \mathrm{C}, 300{ }^{\circ} \mathrm{C}$, and $475{ }^{\circ} \mathrm{C}$ respectively, like the copolymer PCz : POPD-10 : 90 and the peaks were correlated to decomposition events as in the previous case. The char value was observed to be $45 \%$ in this case. A highly pronounced peak of decomposition of $\mathrm{PCz}$ at $220{ }^{\circ} \mathrm{C}$ and a decomposition peak at $475{ }^{\circ} \mathrm{C}$ was associated with POPD, and was also observed in the copolymer PCz : POPD-40:60 with a char value of $19 \%$. The copolymers PCz : POPD-60:40, PCz : POPD-70 : 30, PCz : POPD-90 : 10, Fig. 5(g)-(i), wherein the PCz content was higher than POPD, showed highly pronounced $\mathrm{PCz}$ decomposition peak at $250{ }^{\circ} \mathrm{C}$. The peak due to the decomposition of POPD at $320{ }^{\circ} \mathrm{C}$, solvent evaporation peak at $90{ }^{\circ} \mathrm{C}$, and the $\mathrm{PCz}-$ POPD linkage decomposition peak at $475{ }^{\circ} \mathrm{C}$ were missing. Incidentally, the char value was calculated to be about $8 \%$ in these cases. The decomposition peaks related to POPD and PCz-POPD linkage arose when POPD content in the copolymer was above $60 \%$. This clearly established that $\mathrm{PCz}$ complexions in the copolymer were different from each other when POPD content was above and below $60 \%$ in the copolymer. When the POPD content was higher than that of $\mathrm{PCz}$, the two polymers formed homopolymers which were weakly linked to each other through hydrogen bonding. Table 5 reveals activation energies at different degrees of conversion determined from FlynnWall-Ozawa, Friedman and Vyazokovin methods (plots given in ESI Fig. S6(A-I)†). Activation energies were determined at different degrees of conversion. The values obtained depict that POPD forms linear chains, while $\mathrm{PCz}$ forms short oligomers which are grafted on the POPD chains. This explains independent decomposition events of PCz, POPD, and PCz-POPD linkages. The grafting of $\mathrm{PCz}$ also stimulates the selective decomposition of POPD into char. When PCz amount was higher than POPD in the copolymer, PCz: POPD-60:40, PCz : POPD-70 : 30, and PCz : POPD-90 : 10, only one decomposition event of $\mathrm{PCz}$ was observed. It can therefore be concluded that $\mathrm{PCz}$ forms main polymer chain tending towards random copolymerization, while POPD is interspersed in the main chain. POPD decomposition event overlaps that of $\mathrm{PCz}$ event and the copolymer gives only one decomposition event. The degradation occurred in normal way as pure POPD or pure $\mathrm{PCz}$ yielded quite low char value. Low content of POPD in the copolymer reduced the water absorption and caused the disappearance of moisture evaporation peak. Decomposition of polymers is a complex event in which it splits into small free radicals and molecules and even large ones which interact with each other forming amines, aliphatic and aromatic hydrocarbons, phenols and other products. ${ }^{38,39}$ Some of these reactions lead to charring. Higher POPD content in the copolymer yielded greater charing because of the presence of larger number of benzene rings in the copolymers. The char value in these copolymers was much higher than in pure POPD which resulted from some synergistic mechanism. ${ }^{38,39}$ The above methods therefore justify their use in determining the activation energy of the solid state decomposition of these copolymers. It was observed that the average activation energy of these copolymers determined from each of these methods progressively increased as the amount of POPD in the copolymer increased from 1090\%, except for the composition PCz : POPD-30 : 70, because of certain structural implications as discussed earlier. The average activation energy values of the copolymers PCz : POPD $90: 10$, $70: 30,60: 40,40: 60,30: 70,10: 90$ preferentially from Flynn-Wall-Ozawa method was observed to be 57.11, 61.67, $69.4,128.42,73.85$, and $140.27 \mathrm{~kJ} \mathrm{~mol}^{-1}$. The other methods gave similar values and exactly same trend. We have already observed that last three copolymers have different monomer complexion than the other three copolymers which is also reflected in their activation energies.

\section{Conclusion}

Polycarbazole and poly(o-phenylenediamine) were successfully copolymerized via ultrasonication technique. Random copolymerization ratio was confirmed by Fineman-Ross equation. Ultraviolet-visible spectroscopy studies revealed the variation in the optical properties as the copolymer composition changed from $90 \% \mathrm{PCz}$ content $(75 \%-\mathrm{CHN})$ to $10 \% \mathrm{PCz}$ content $(35 \%-\mathrm{CHN})$ which also confirmed random copolymer formation while transmission electron microscopy showed that the copolymers adopted the morphology of polycarbazole/ poly(o-phenylenediamine) depending upon the composition. Cyclic voltammetry revealed that peak oxidation potential of both polycarbazole and poly(o-phenylenediamine) increased in the copolymers while their peak reduction potentials decreased. Thermal analysis revealed random copolymer formation with two different complexions and showed one or more than one decomposition events depending upon copolymer composition. The average activation energy of decomposition of the copolymers containing $90 \%$, 70\%, 60\%, 40\%, $30 \%$ and $10 \%$ polycarbazole from Flynn-Wall-Ozawa method was observed to be $57.11 \mathrm{~kJ} \mathrm{~mol}^{-1}, 61.67 \mathrm{~kJ} \mathrm{~mol}^{-1}, 69.4 \mathrm{~kJ}$ $\mathrm{mol}^{-1}, 128.42 \mathrm{~kJ} \mathrm{~mol}^{-1}, 73.85 \mathrm{~kJ} \mathrm{~mol}^{-1}$, and $140.27 \mathrm{~kJ} \mathrm{~mol}^{-1}$. Fluorescence analysis confirmed that the quantum yield was proportional to the amount of polycarbazole/poly(o-phenylenediamine) in the copolymer. The copolymer can be used in designing hetero-structured devices for their application in organic light emitting diodes (OLEDs).

\section{Acknowledgements}

The corresponding author DrUfana Riaz wishes to acknowledge the DST-SERB for granting major research project vide sanction number SB/S1/PC-070/2013. One of the co-author Mrs Sapana Jadoun also wishes to acknowledge the DST-SERB for Senior Research fellowship (SRF) under the same project. The authors acknowledge the Sophisticated Analytical Instrumentation Facility at All India Institute of Medical Sciences (AIIMS) for the TEM analysis and the Advance instrumentation Research Facility (AIRF) at JNU, New Delhi, for the fluorescence analysis. 


\section{References}

1 L. Dou, Y. Liu, Z. Hong, G. Li and Y. Yang, Low-Bandgap Near-IR Conjugated Polymers/Molecules for Organic Electronics, Chem. Rev., 2015, 115, 12633-12665.

2 U. Riaz, S. M. Ashraf and J. Kashyap, Enhancement of photocatalytic properties of transitional metal oxides using conducting polymers: A mini review, Mater. Res. Bull., 2015, 71, 75-90.

3 U. Riaz, S. M. Ashraf, R. Raza, K. Kohli and J. Kashyap, Sonochemical Facile Synthesis of Self-Assembled Poly (ophenylenediamine)/Cobalt Ferrite Nanohybrid with Enhanced Photocatalytic Activity, Ind. Eng. Chem. Res., 2016, 55(22), 6300-6309.

4 U. Riaz, S. M. Ashraf, T. Fatima and S. Jadoun, Tuning the spectral, morphological and photophysical properties of sonochemically synthesized poly (carbazole) using acid Orange, fluorescein and rhodamine 6G, Spectrochim. Acta, Part A, 2017, 173, 986-993.

5 A. Casey, S. D. Dimitrov, P. S. Tuladhar, Z. Fei, M. N. guyen, Y. Han, T. D. Anthopoulos, J. R. Durrant and M. Heenay, Effect of Systematically Tuning Conjugated Donor Polymer Lowest Unoccupied Molecular Orbital Levels via Cyano Substitution on Organic Photovoltaic Device Performance, Chem. Mater., 2016, 28, 5110-5120.

6 K. K. Nanda, S. Swain, B. Satpati, L. Besra, B. Mishra and Y. S. Chaudhary, Enhanced Photocatalytic Activity and Charge Carrier Dynamics of Hetero-Structured OrganicInorganic Nano-Photocatalysts, ACS Appl. Mater. Interfaces, 2015, 7, 7970-7978.

7 A. Takai, Z. Chen, X. Yu, N. Zhou, T. J. Marks and A. Facchetti, Annulated Thienyl-Vinylene-Thienyl Building Blocks for $\pi$-Conjugated Copolymers: Ring Dimensions and Isomeric Structure Effects on $\pi$-Conjugation Length and Charge Transport, Chem. Mater., 2016, 28, 5772-5783.

8 Y. J. Hwang, T. Earmme, B. A. E. Courtright, F. N. Eberle and S. A. Jenekhe, n-Type Semiconducting Naphthalene DiimidePerylene Diimide Copolymers: Controlling Crystallinity, Blend Morphology, and Compatibility Toward HighPerformance All-Polymer Solar Cells, J. Am. Chem. Soc., 2015, 137, 4424-4434.

9 S. Holliday, R. S. Ashraf, C. B. Nielson, M. Kirkus, J. A. Rohr, C. H. Tan, E. C. Fregoso, A. S. Knall, J. R. Durrant, J. Nelson and I. McCulloch, A Rhodanine Flanked Nonfullerene Acceptor for Solution-Processed Organic Photovoltaics, $J$. Am. Chem. Soc., 2015, 137, 898-904.

10 A. Takai, Z. Chen, X. Yu, N. Zhou, T. J. Marks and A. Facchetti, Annulated Thienyl-Vinylene-Thienyl Building Blocks for $\pi$-Conjugated Copolymers: Ring Dimensions and Isomeric Structure Effects on $\pi$-Conjugation Length and Charge Transport, Chem. Mater., 2016, 28, 5772-5783.

11 U. Riaz, R. Jahan, S. Ahmad and S. M. Ashraf, Copolymerization of poly (1-naphthylamine) with aniline and $o$-toluidine, J. Appl. Polym. Sci., 2008, 108(4), 2604-2610.

12 M. Jaymand, M. Hatamzadeh and Y. Omidia, Modification of polythiophene by the incorporation of processable polymeric chains: Recent progress in synthesis and applications, Prog. Polym. Sci., 2015, 47, 26-69.

13 X. Zhou, N. Ai, Z.-H. Guo, F.-D. Zhuang, Y.-S. Jiang, J.-Y. Wang and J. Pei, Balanced ambipolar organic thinfilm transistors operated under ambient conditions: Role of the donor moiety in BDOPV-based conjugated copolymers, Chem. Mater., 2015, 27, 1815-1820.

14 M. Gao, J. Subbiah, P. B. Geraghty, M. Chen, B. Purushothaman, X. Chen, T. Qin, D. Vak, F. H. Scholes, S. E. Watkins, M. Skidmore, G. J. Wilson, A. B. Holmes, D. J. Jones and W. W. H. Wong, Chem. Mater., 2016, 28, 3481-3487.

15 Z. Peng, Z. Bao and M. E. Galvin, Oxadiazole-Containing Conjugated Polymers for Light-Emitting Diodes, Adv. Mater., 1998, 10, 680-684.

16 J. Kido, G. Harada and K. Nagai, Electroluminescent poly (arylene ether) containing both hole-transporting and electron-transporting units, Chem. Lett., 1996, 2, 161-170.

17 N. M. Adamczyk, A. A. Dameron and S. M. George, Molecular layer deposition of poly ( $p$-phenylene terephthalamide) films using terephthaloyl chloride and $p$-phenylenediamine, Langmuir, 2008, 24, 2081-2089.

18 X.-G. Li, H.-Y. Wang and M.-R. Huang, Synthesis, filmforming, and electronic properties of $o$-phenylenediamine copolymers displaying an uncommon tricolor, Macromolecules, 2007, 40, 1489-1496.

19 X.-G. Li, M.-R. Huang and Y. Yang, Synthesis and characterization of $o$-phenylenediamine and xylidine copolymers, Polymer, 2001, 42, 4099-4107.

20 Y. Kong, X. Shan, Y. Tao, Z. Chen and H. Xue, Synthesis of Poly (o-phenylenediamine-co-o-aminophenol) via Electrochemical Copolymerization and its Electrical Properties, J. Electrochem. Soc., 2013, 160, G96-G101.

21 U. Riaz, S. M. Ashraf, S. Aleem, V. Budhiraja and S. Jadoun, Microwave-assisted green synthesis of some nanoconjugated copolymers: characterisation and fluorescence quenching studies with bovine serum albumin, New J. Chem., 2016, 40, 4643-4653.

22 L. Zhang, W. Yuan and Y. Yan, In situ UV-vis spectroelectrochemical studies on the copolymerization of $o$-phenylenediamine and $o$-methoxy aniline, Electrochim. Acta, 2013, 113, 218-228.

$23 \mathrm{~S}$. Bilal and R. Holze, Electrochemical copolymerization of $o$ toluidine and $o$-phenylenediamine, J. Electroanal. Chem., 2006, 592, 1-13.

24 L. A. Hernandez, M. A. Del Vallei, F. J. Armijoi, F. R. Diazi and G. Louarn, Electro-oxidation of 1-amino-9,10anthraquinone and $O$-phenylenediamine and the Influence of Its Copolymerization in the Modified Electrode Properties, Electrochemistry, 2013, 81, 954-965.

25 U. Riaz, S. M. Ashraf, S. K. Saroj, M. Zeeshan and S. Jadoun, Microwave-assisted solid state intercalation of Rhodamine B and polycarbazole in bentonite clay interlayer space: structural characterization and photophysics of double intercalation, $R S C$ Adv., 2016, 6(41), 34534-34545.

26 I. B. Ceballos, F. Hermerschmidt, A. V. Akkuratov, D. K. Susarova, P. A. Troshin and S. A. Choulis, High- 
Performing Polycarbazole Derivatives for Efficient SolutionProcessing of Organic Solar Cells in Air, ChemSusChem, 2015, 8, 4209-4215.

27 H. E. Oğuztürk, S. Tirkes and A. M. Onal, Electrochemical synthesis of new conjugated polymers based on carbazole and furan units, J. Electroanal. Chem., 2015, 750, 1-8.

28 U. Riaz and S. M. Ashraf, Microwave-assisted solid state in situ polymerization and intercalation of poly (carbazole) between bentonite layers: effect of microwave irradiation and gallery, J. Phys. Chem. C, 2012, 116, 12366-12372.

29 T. Ozawa, A new method of analyzing thermogravimetric data, Bull. Chem. Soc. Jpn., 1965, 38, 1881-1886.

30 J. H. Flynn, The 'temperature integral'-its use and abuse, Thermochim. Acta, 1997, 300, 83-92.

31 C. D. Doyle, Kinetic Analysis of Thermogravimetric Data, J. Appl. Polym. Sci., 1961, 5, 285-292.

32 M. Fineman and S. D. Ross, Linear method for determining monomer reactivity ratios in copolymerization, J. Polym. Sci., 1995, 5, 259-262.

33 V. Jankus and A. P. Monkman, Is Poly(Vinylcarbazole) a Good Host for Blue Phosphorescent Dopants in PLEDs? Dimer Formation and Their Effects on the Triplet Energy Level of Poly( $N$-Vinylcarbazole) and Poly( $N$-Ethyl-2Vinylcarbazole), Adv. Funct. Mater., 2011, 21, 3350-3356.
34 S. A. Bagnich, S. Athanasopoulos, A. Rudnick, P. Schroegel, I. Bauer, N. C. Greenham, P. Strohriegl and A. Kohler, Excimer Formation by Steric Twisting in Carbazole and Triphenylamine-Based Host Materials, J. Phys. Chem. C, 2015, 119, 2380-2387.

35 A. Iraqi, T. G. Simmance, H. Yi, M. Stevenson and D. G. Lidzey, Preparation and Properties of 4-Dialkylaminophenyl $N$-Functionalized 2,7-Linked Carbazole, Polymers, Chem. Mater., 2006, 180, 5789-5797.

36 X. G. Li, M.-R. Huang, W. Feng, M.-F. Zhu and Y.-M. Chen, Facile synthesis of highly soluble copolymers and submicrometer particles from ethylaniline with anisidine and sulfoanisidine, Polymer, 2004, 45, 101-115.

37 G. Inzlet, Formation and redox behaviour of polycarbazole prepared by electropolymerization of solid carbazole crystals immobilized on an electrode surface, J. Solid State Electrochem., 2003, 7, 503-510.

38 S. Tiptipakorn, S. D. Ando, K. Hemvichian and S. Rimdusit, Thermal degradation behaviors of polybenzoxazine and silicon-containing polyimide blends, Polym. Degrad. Stab., 2007, 92, 1265-1278.

39 T. Agag and T. Takeichi, Novel method for preparation of poly(benzoxazinone-imide), Polym. Chem., 2000, 38, 16471655. 